\title{
To Anion-m or not to Anion-m: The Case of Anion-Binding to Divalent Fluorinated Pyridines in the Gas Phase
}

\author{
Melanie Göth, ${ }^{[a]}$ Felix Witte, ${ }^{[a]}$ Marcel Quennet, ${ }^{[a]}$ Philip Jungk, ${ }^{\left[{ }^{[a]}\right.}$ Gabriel Podolan, ${ }^{[a]}$ Dieter Lentz, ${ }^{[b]}$ \\ Hans-Ulrich Reissig, ${ }^{*[a]}$ Beate Paulus, ${ }^{*[a]}$ and Christoph A. Schalley ${ }^{*[a]}$
}

\begin{abstract}
A series of mono- and divalent fluorinated pyridine derivatives is investigated by electrospray ionization (tandem) mass spectrometry and quantum chemical calculations with respect to their capability to bind anions in the gas phase. The pyridine derivatives differ not only in valency, but also with regard to the degree of fluorination of the pyridine rings, the positions of the fluorine atoms, the rigidity of the spacers connecting the two pyridines in the divalent compounds, and the relative configuration. While the monovalent compounds did not form anion complexes, the divalent analogues exhibit anion binding even to weakly coordinating anions such as tetrafluoroborate. Three different tandem mass spectrometric experiments were applied to rank the gas-phase binding energies: (i) collision-induced dissociation (CID) experiments in a Fourier-transform ion-cyclotron-resonance (FTICR) mass spectrometer on two different, simultaneously mass-selected complexes with different receptors, (ii) determination of the collision energy required to fragment $50 \%$ of the mass-selected complexes in an ESI-QToF mass spectrometer, and (iii) CID of heterodimers formed from two different, competing pyridine receptors and indigo carmine, a dianion with two identical binding sites. All three experiments result in consistent binding energy ranking. This ranking reveals surprising features, which are not in agreement with binding through anion- $\pi$ interactions. Density functional theory (DFT) calculations comparing different potential binding modes provide evidence that the ranking can instead nicely be explained, when C$\mathrm{H}$...anion interactions with the spacers are invoked.
\end{abstract}

\section{Introduction}

Besides well-known and intensely studied non-covalent forces such as hydrogen bonding, ${ }^{[1]} \pi-\pi$ stacking, ${ }^{[2]}$ and cation- $\pi$ interactions, ${ }^{[3][3]}$ the non-covalent bonds between anions and $\pi$ systems have attracted broad interest recently. ${ }^{[4]}$ Four different binding motifs were experimentally observed: (i) the $\mathrm{C}-\mathrm{H} \cdots \mathrm{X}$ hydrogen bond, (ii) the mostly covalent Meisenheimer complex, (iii) the weakly covalent anion-donor-m-acceptor interaction and

[a] M. Göth, F. Witte, M. Quennet, Dr. P. Jungk, Dr. G. Podolan, Prof. Dr. H.-U. Reissig, Prof. Dr. B. Paulus, Prof. Dr. C. A. Schalley Institut für Chemie und Biochemie Freie Universität Berlin

Takustraße 3, 14195 Berlin, Germany

E-Mail: b.paulus@fu-berlin.de; c.schalley@fu-berlin.de

[b] Prof. Dr. D. Lentz

Institut für Chemie und Biochemie

Freie Universität Berlin

Fabeckstraße 34-36, 14195 Berlin, Germany

Supporting information for this article is given via a link at the end of the document. (iv) the non-covalent anion- $\pi$ interaction. [ 5] The anion- $\pi$ interaction can be described as an attractive force between the anion and the positive $\pi$-acidic surface of an electron-deficient aromatic ring with permanent quadrupole moment. The anion is then located above the center of the aromatic ring. [6 ] Hexafluorobenzene and triazine, for example, form complexes with anions - in contrast to benzene, which has a quadrupole moment with negative $\pi$ face. Gas-phase IR spectroscopy revealed that subtle changes in the structure of the aromatic molecule can cause a complete shift from one binding mode to another one. ${ }^{[7]}$ While hexafluorobenzene binds a chloride ion above the aromatic ring, pentafluorobenzene realizes a $\mathrm{C}-\mathrm{H} \cdots \mathrm{Cl}$ interaction as the $\pi$-acidity of the aromatic ring is reduced and the $\mathrm{C}-\mathrm{H}$ bond is strongly polarized.

Although the origins of research on anion- $\pi$-interactions date back to the 1980 ies, ${ }^{[8]}$ theoretical studies by Deyà et al. ${ }^{[9]}$ and Mascal et al. ${ }^{[10]}$ published in 2002 attracted the attention of a broader supramolecular community, since the anion-m interaction was predicted to be significantly attractive $(\sim 20-50 \mathrm{~kJ} / \mathrm{mol})$ in the gas phase. As anions are involved in many chemical and biochemical processes, research in this field is motivated by the desire for new and specific anion receptors ${ }^{[11]}$ and transport systems. ${ }^{[12]}$ In the last years, a huge number of publications appeared on a broad variety of aspects related to anion- $\pi$ interactions. ${ }^{[4 \mathrm{~g}, 13]}$ In many of these complexes, other comparatively strong attractive forces such as hydrogen bonding or stronger electrostatic interactions are the primary binding force. The anion- $\pi$-interaction itself is relatively weak in solution and thus usually observed as a modulation of these major effects. It is thus difficult to differentiate, whether the anion- $\pi$ interaction is attractive or repulsive in these complexes. Consequently, experimental evidence for "pure" anion- $\pi$ interactions is still hard to gather and certainly not commonplace. ${ }^{[14]}$

Tandem mass spectrometry in concert with theory can help circumventing this difficulty, because it offers the advantage that non-solvated anion-receptor complexes can be examined. In the gas phase, the anion- $\pi$ interactions do not compete with solvation or counterion effects. Consequently, no additional primary interaction is required and the observation of an anionhost complex directly implies an attractive force between both. This advantage of the gas phase, however, comes at a price, as the major challenge is to determine the binding mode of these complexes. It is thus pivotal to combine the experiments with high-level calculations.

Here, we present a combined mass spectrometric and quantum chemical study of non-covalent complexes of the fluorinated mono- and divalent aminopyridines and one divalent alkoxypyridine depicted in Figure 1 with different anions. 
<smiles>CN(C)c1ccncc1</smiles><smiles>CN(C)c1ccncc1F</smiles>

M1<smiles>CN(C)c1cc(F)nc(F)c1</smiles><smiles>CCN(C)c1cnc(F)c(F)c1F</smiles><smiles>CN(C)c1cc(F)nc(F)c1F</smiles><smiles>CN(F)c1c(F)nnc(F)c1F</smiles>

M8<smiles>CN(C)c1c(F)cncc1F</smiles>

D1<smiles>CN(C)c1c(F)c(F)nc(F)c1F</smiles>

D4<smiles>CCOC(=O)c1cncc(F)c1N(C)C1CCCCC1c1c(F)cncc1F</smiles><smiles>Cc1ccc(N2CN(c3cc(F)nc(F)c3)C3CCCCC32)cc1</smiles>
DC3<smiles>CN(CCN(C)c1cc(F)nc(F)c1)c1cc(F)nc(F)c1</smiles>

D2

D5<smiles>CN(C)c1ccnc(F)c1</smiles>

M3<smiles>CN(C)c1c(F)cncc1F</smiles>

M4
$M 7$<smiles></smiles>

D3<smiles>Fc1nc(F)c(OCCOc2c(F)c(F)nc(F)c2F)c(F)c1F</smiles>
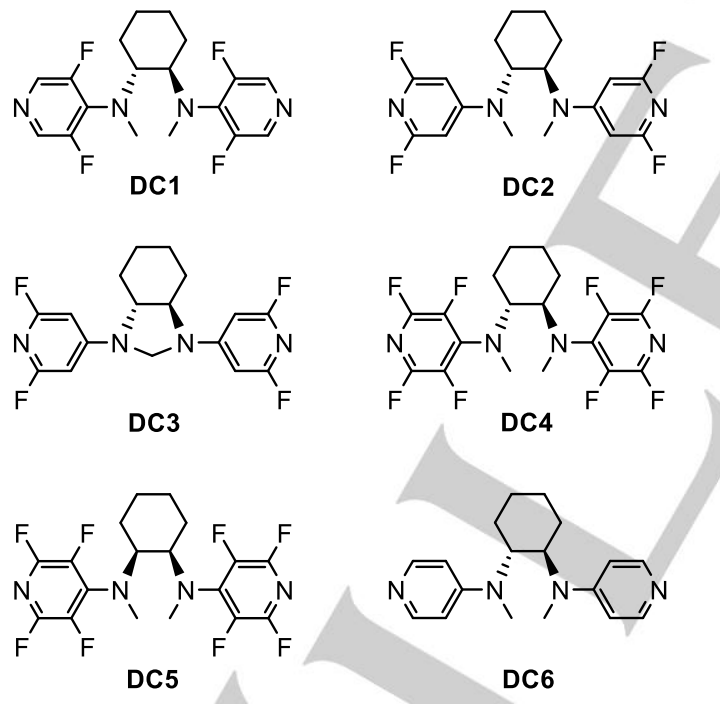

Figure 1. Fluorinated mono- and divalent pyridines with different numbers and positions of fluoro substituents, flexible ethylene (D1-D5) or rigid cyclohexane spacers (DC1-DC6) and different relative configuration (DC4 vs. DC5).

Pyridines were used as they are already $\pi$-electron-deficient aromatic compounds, which are further made $\pi$-acidic by the fluorine substituents. Theoretical studies have shown that pentafluoropyridine binds anions even stronger than hexafluorobenzene. ${ }^{[6]}$ The pyridines used here differ with respect to several features so that comparison of different series will provide more detailed insight into binding trends: (i) Mono- and divalent compounds with the same degree of fluorination (e.g. M8, D4 and D5) provide insight into the role of sandwich-like complexes and the effect of the nitrogen or oxygen substituents. (ii) Comparing divalent pyridines with flexible ethylene spacers with those that bear a rigid cyclohexane spacer (e.g. D4 and DC4) reveal whether conformational fixation plays a role. (iii) Diastereomers such as DC4 and DC5 refine these arguments that are based on the idea that preorganization of the two pyridine rings in the divalent receptors might play an important role. (iv) Different degrees of fluorination (e.g. D1, D3 and D4) show how important fluorination is. (v) Isomers, which differ only with respect to the positions of the fluorine substituents (e.g. D1 and D2), may shed light on the binding mode.

\section{Results and Discussion}

Conceptual Considerations. As briefly discussed above, anion- $\pi$ interactions are usually weak in solution due to the competing effects of counterions and solvent. A study of the anion gas-phase binding thus has its advantages, but suffers from the lack of direct structural information. As the determination of exact absolute binding energies in the gas phase is not a trivial task and requires specialized equipment, $\left[{ }^{15}\right]$ we aim at establishing a ranking of relative binding forces of anions to the different pyridine derivatives discussed above. On one hand, the determination of relative binding strengths for example by experiments, in which pairwise competitions are monitored, is particularly suited, when the binding energy differences are small. On the other hand, a comparison between the ranking expected for anion- $\pi$ interactions and that obtained by experiment may well provide qualitative insight into the binding mode, which can then be complemented by theory.

In order to cross-check the binding ranking obtained, three different experiments were performed: Method A: Two complexes with the same anion, but different receptors were ionized, brought into the cell of a Fourier-transform ioncyclotron-resonance mass spectrometer (FTICR), where both complexes are simultaneously mass-selected and fragmented at increasing collision energies. The more weakly bound complex will start to fragment at lower collision energies and the intensity ratio of both signals shift towards the more strongly bound complex. As the mass differences between the two complexes are small, we do not expect mass discrimination to play a significant role. Method B: Each complex was furthermore studied by collision-induced dissociation and the collision energy, at which $50 \%$ of the parent ion had dissociated, was determined and compared for the different complexes (survival yield method). ${ }^{[16]}$ Method C: Finally, a direct competition was achieved by using indigo carmine (3,3'-dioxo-2,2'-bisindolyden-5,5'disulfonic acid disodium salt), a dianion with a rigid spacer separating the two sulfonate groups. Mixing two different receptors with this dianion generated the homo- and heterodimers of two receptor molecules bound to the dianion simultaneously. Mass-selection of the heterodimer followed by CID also provides insight, which of the receptors binds more 


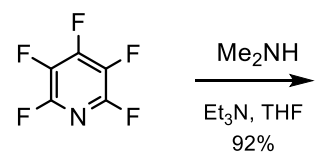<smiles>CN(C)c1c(F)c(F)nc(F)c1F</smiles>

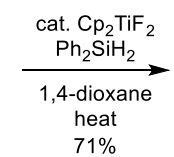

M8<smiles>CC(=O)OCc1c(F)c(F)nc(F)c1N(C)[C@@H]1CCCC[C@H]1N(c1c(F)nc(F)c(F)c1F)c1c(F)c(F)nc(F)c1F</smiles>

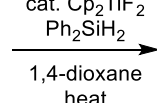
$46 \%$<smiles>NC1CCCCC1N</smiles>
$30 \%$<smiles>Fc1cc(N[C@@H]2CCCC[C@H]2Nc2cc(F)nc(F)c2)cc(F)n1</smiles>
$\underset{\mathrm{THF}}{\stackrel{\mathrm{NaH}, \mathrm{Mel}}{\longrightarrow}}$ (+ $61 \%$ regioisomers)<smiles>Fc1nc(F)c(F)c(OCCOc2c(F)c(F)nc(F)c2F)c1F</smiles>

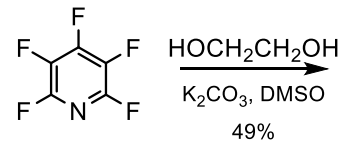

D5 heat

\section{$85 \%$}<smiles>CN(C)c1c(F)cncc1F</smiles>

M4

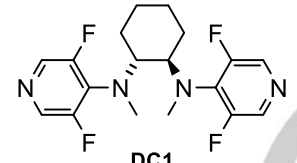

(4)

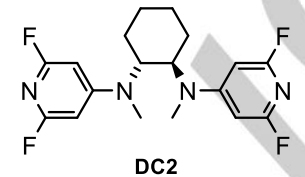

DC2

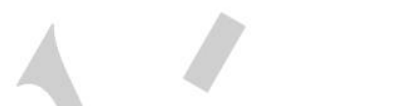

benzene/hexane (1:1) (D4) and directly after column chromatography (DC4) gave crystals suitable for single crystal X-ray structure determinations. Both compounds crystallize in the monoclinic space group $\mathrm{C} 2 / \mathrm{c}$, with half a molecule forming the asymmetric unit and both molecules possess crystallographic C2 symmetry. The molecular structure and the atom-numbering scheme are depicted in Figure 3.

Due to a less rigid structure, the fluorinated pyridine moieties of D4 are in closer contact with the shortest distance of $3.13 \AA$ found between $\mathrm{C} 4$ and its symmetry related atom C4i. In contrast, the shortest carboncarbon distance (C4..C4i) between the aromatic ring systems of DC4 amounts to $3.94 \AA$ A However, a short fluorine contact exists between F3 and

Figure 2. Syntheses of 4-aminopyridines M8 and M4 as well as divalent compounds DC4, DC1, DC2, and D5.

strongly. This method is a qualitative variant of Cooks' kinetic method. ${ }^{[17]}$

It is much more conclusive to compare the experimental binding sequences with trends calculated for the different binding modes with high-level quantum theoretical methods than to try to theoretically match individual experimental binding energies. Also, this argument supports that the determination of the ranking is a reasonable approach.

Synthesis of fluorinated 4-aminopyridine derivatives and crystal structures of D4 and DC4. The experimentally studied 4-aminopyridine receptors were prepared by nucleophilic substitution at the 4-position of pentafluoropyridine or 2,4,6-trifluoropyridine followed by regioselective defluorination or $\mathrm{N}$-methylation. ${ }^{[18]}$ This approach is exemplified by the reactions leading to compounds M4, M8, DC1, DC2 and D4 (Figure 2). Pentafluoropyridine and dimethylamine react to provide exclusively the 4-amino-substituted pyridine derivative M8 that was exposed to a novel titanocenium-catalyzed hydrodefluorination reaction. [18a] Target compound M4 was regioselectively obtained in overall good yield (equation 1 ).

The divalent compounds DC4 and DC1 were prepared with reasonable efficiency following the same route (equation 2). For divalent 4-aminopyridine derivative DC2 it was advantageous to introduce the $\mathrm{N}$-methyl groups after the nucleophilic substitution in order to achieve at least moderate regioselectivity in the nucleophilic substitution reaction (equation 3). ${ }^{[18]}$ The divalent 4alkoxy-substituted pyridine derivative D5 was analogously prepared from pentafluoropyridine and ethylene glycol under basic conditions (equation 4).

Crystallization of the divalent 4-aminopyridine derivatives D4 and DC4 with a flexible and a rigid spacer, respectively, from
C4i (3.26 A). In D4 and DC4, the amino nitrogen atom adopts a gauche conformation with dihedral angles of $69.0^{\circ}$ and $-55.2^{\circ}$, respectively.

a) D4

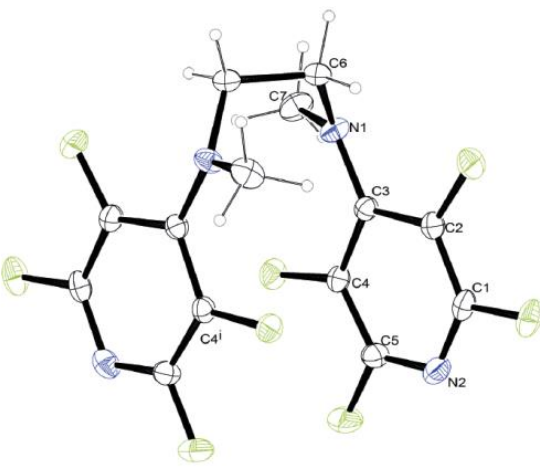

b) DC4

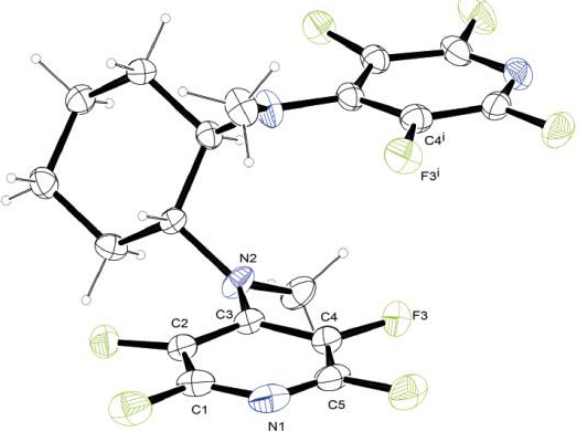

Figure 3. Molecular structures (ORTEP ${ }^{[19]}$ ) of a) D4 and b) DC4. Ellipsoids are drawn at a $50 \%$ probability level. 
Table 1. Detected complexes of anions with divalent pyridines.

\begin{tabular}{|c|c|c|c|c|c|c|c|}
\hline & $\mathrm{Cl}^{-}$ & $\mathrm{Br}$ & $\mathbf{I}^{-}$ & $\mathrm{NO}_{3}{ }^{-}$ & $\mathrm{BF}_{4^{-}}$ & $\mathrm{PF}_{6}{ }^{-}$ & $\mathrm{H}_{3} \mathrm{CSO}_{3}{ }^{-}$ \\
\hline D1 & - & - & - & - & - & - & - \\
\hline D2 & + & + & + & + & + & + & + \\
\hline D3 & + & + & - & - & - & - & - \\
\hline D4 & + & + & + & + & + & - & + \\
\hline D5 & + & + & + & + & + & - & - \\
\hline DC1 & - & - & - & - & - & - & - \\
\hline DC2 & + & + & + & + & + & - & + \\
\hline DC3 & + & + & + & + & - & - & + \\
\hline DC4 & + & + & + & + & + & - & + \\
\hline DC5 & + & + & - & + & - & - & + \\
\hline DC6 & - & - & - & - & - & - & \\
\hline
\end{tabular}

In both compounds, the amino nitrogen atoms exhibit an almost trigonal planar substitution by the adjacent carbon atoms with a sum of the bond angles of $358.0^{\circ}$ (D4) and $359.4^{\circ}$ (DC4). As expected, the $\mathrm{C}-\mathrm{N}$ distances to the aromatic ring are about $0.1 \AA$ shorter than those to the $\mathrm{sp}^{3}$ carbon atoms of the substituents.

Generation of gaseous anion-receptor complexes by ESI mass spectrometry. The three monovalent 4-aminopyridine derivatives M4, M5, and $\mathbf{M 8}$ (Figure 1) had been synthesized to be examined as first test systems. They feature different degrees of fluorination as well as different positions of fluorine substituents and were regarded therefore as meaningful examples. As all attempts failed to ionize intact complexes of the halides $\mathrm{Cl}^{-}, \mathrm{Br}^{-}, \mathrm{I}^{-}$, and of $\mathrm{NO}_{3}{ }^{-}$or of weakly coordinating anions $\mathrm{BF}_{4}^{-}$and $\mathrm{PF}_{6}^{-}$with these aminopyridines, the remaining monovalent fluorinated aminopyridines where thus not synthesized, but studied only theoretically. Among the divalent receptors, D1, DC1 and DC6 did not yield any detectable complexes with the anions tested (Table 1). In marked contrast, electrospray ionization of the divalent pyridine analogues D2-D5 and DC2-DC5 provided access to quite abundant complex ions. Some of the receptors even bind to the weakly coordinating $\mathrm{BF}_{4}$ anion. Even $\mathrm{PF}_{6}{ }^{-}$is bound by one of the divalent receptors, i.e. D2. This result is particularly intriguing as D2 bears only doubly fluorinated pyridine rings. It is certainly counterintuitive for anion$\pi$-interactions that this pyridine derivative forms complexes, while the structurally equivalent, but more highly fluorinated receptors D3 and D4 do not.

Gas-phase ranking of anion binding to divalent fluorinated pyridines. Figure 4 shows two representative experiments, in which two receptor/chloride complexes are compared pairwise in a CID experiment (method A). Gradually increasing the collision energy leads to the preferential dissociation of the more weakly bound complex. For pairs of receptors that exhibit large differences in binding energies, this experiment is difficult to do or even impossible, because their chloride complexes appear in the mass spectrum with substantially different intensities. In extreme cases, one is even absent due to the strong competition. Nevertheless, pairs of receptors with similar binding energies can be compared easily and a binding energy ranking is obtained by proceeding step-wise from one pair to the next. It should also be mentioned that the DC4/DC5 pair could not directly be compared because both receptors differ only in their relative configuration; both have the same elemental composition and thus form complexes with the same $m / z$ value. Here, the comparison of both receptors with others provides insights into their relative binding strengths. Using as many pairs as possible demonstrates the binding strength ranking to be consistent (Figure S1, Table S2). From these measurements, we obtain the following ranking:

$$
\mathrm{DC} 2>\mathrm{DC} 4>\mathrm{D} 2>\mathrm{D} 4 \approx \mathrm{DC} 3>\mathrm{D} 5>\mathrm{DC} 5>\mathrm{D} 3
$$

\section{Method A}

a) Degree of fluorination

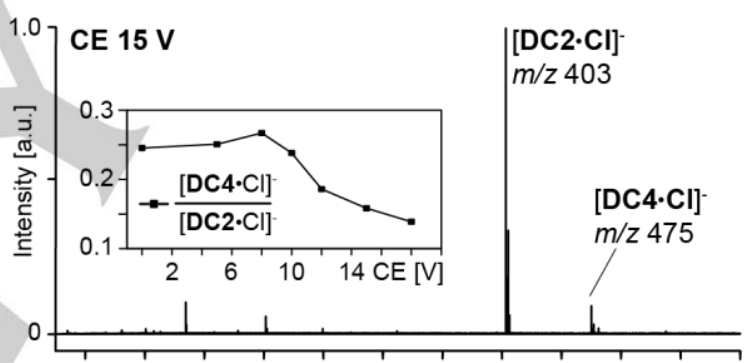

b) Flexible vs. rigid

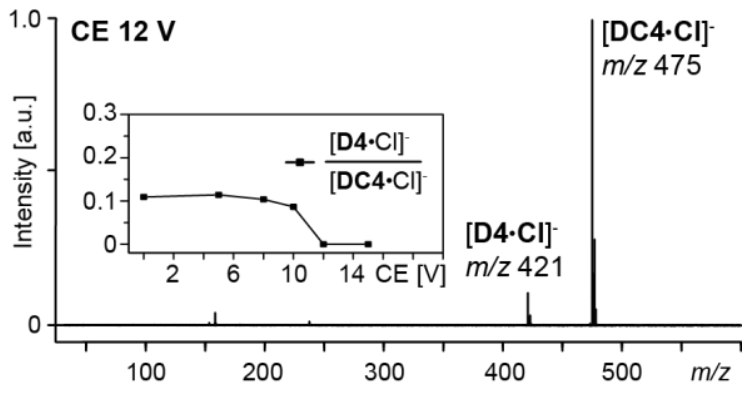

Figure 4. Method A. CID mass spectra for two simultaneously isolated chloride complexes. a) DC2 vs. DC4: Different degrees of fluorine substitution. b) D4 vs. DC4: Flexible and rigid spacers. Insets: Plot of the intensity depletion of the weaker chloride complex relative to the stronger complex over increasing collision energies $(\mathrm{CE})$

Clearly, the pairs DC2/DC4 (Figure 4a) and D2/D4 (Figure S1a) reveal the derivatives doubly fluorinated in the 2,6positions of the pyridine rings to bind more strongly to chloride than their perfluoro analogues. Also, the more rigid spacers in DC2 and DC4 promote the binding strength, while the flexible 
ethylene spacer in D2 and D4 reduces it (Figure 4b and Figure S1b). The rather weak binding of DC3, which has the lowest conformational flexibility due to the methylene bridge, evidences a clear dependence on structural details. In addition, a pronounced stereochemical difference is observed, which puts the trans-configured isomer DC4 among the strongest binders, while the corresponding cis-isomer DC5 is among the weakest ones. The series D2 > D4 > D3 also shows that the binding strength does not only depend on the degree of fluorine substitution. As D1 does not form any anion complexes and D3 is weakly interacting with chloride, fluorine substituents in the 3,5-positions of the pyridine ring appear not to be advantageous. The sequence of D4 > D5 shows that substitution of the $\mathrm{N}$ methylamino units by oxygen atoms does not lead to a stronger interaction with chloride.

\section{Method B}

a) $\mathrm{CID}$ experiment, $\mathrm{CE}=2 \mathrm{~V}$

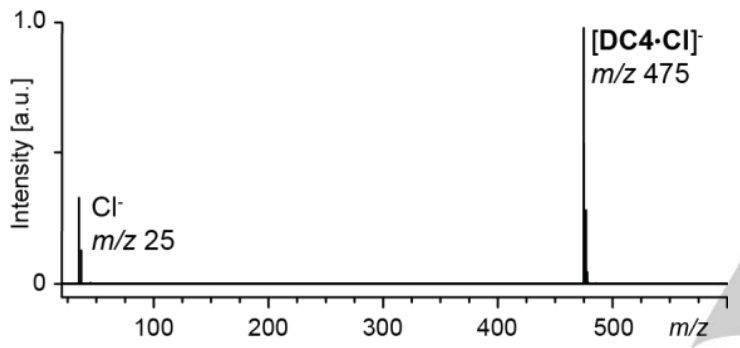

b) Dissociation of [DC4. Cl]

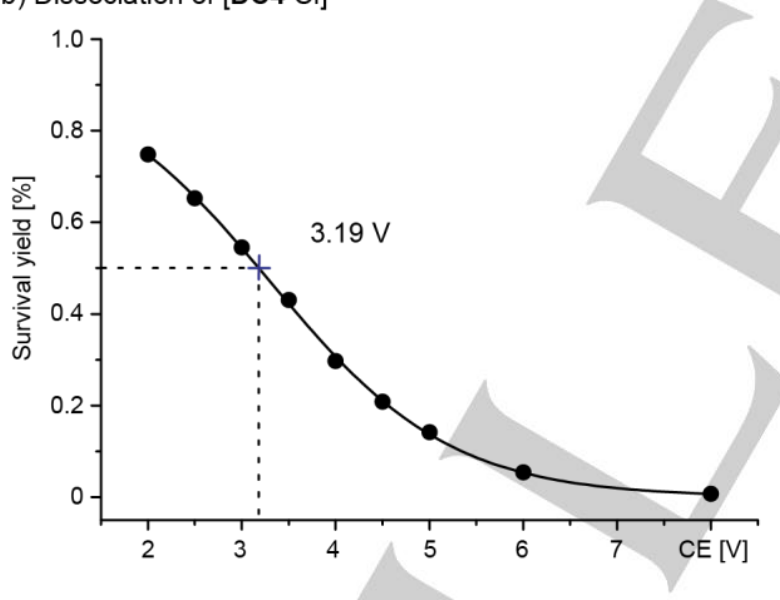

Figure 5. Method B. a) Mass spectrum of the $\mathrm{m} / \mathrm{z}$-selected complex [DC4. $\mathrm{Cl}$ ] at $2 \mathrm{~V}$ collision energy (CE). b) Plot of the survival yield against the CE and fit with a sigmoidal function. At a CE of $3.19 \mathrm{~V}, 50 \%$ of the complex has dissociated.

The ranking of chloride complex binding strengths obtained by method $A$ is confirmed by the application of the survival yield approach (method B). Figure 5 displays exemplarily for the complex $\mathbf{D C 4} \cdot \mathrm{Cl}^{-}$a typical experiment, during which the collision energy is increased in a stepwise manner by increasing the transfer collision energy of the ions. The ratio of complex and free chloride is determined for each step in order to identify at which collision energy $50 \%$ of the ions have fragmented (Figure
$5 b)$. This experiment is somewhat limited for very weakly bound complexes, as the collision energy, at which $50 \%$ of the complexes have fragmented is then below the instrument's minimum (start) value of $2 \mathrm{~V}$. However, the degree of fragmentation at this collision energy can be compared even for those complexes and thus, a ranking can be obtained. Table 2 reports the $50 \%$ survival yield collision energies for all complexes that bind the chloride sufficiently strong. The ranking of binding strengths obtained here is consistent with that obtained with method $\mathrm{A}$ :

$$
\text { DC2 > DC4 > D2 > DC3 > D4 (> D5 DC5 D3) }
$$

Table 2. Collision energy at $50 \%$ complex dissociation for the chloride complexes of different divalent pyridine derivatives. Values correspond to the average survival yield of measurements (in triplicate). Data is well reproducible (standard deviation $<1 \%$ ).

\begin{tabular}{ll}
\hline D2 & $3.08 \mathrm{~V}$ \\
D4 & $<2 \mathrm{~V}$ \\
DC2 & $5.36 \mathrm{~V}$ \\
DC3 & $2.21 \mathrm{~V}$ \\
DC4 & $3.19 \mathrm{~V}$ \\
\hline
\end{tabular}

Finally, method $C$ has been applied, in which two of the divalent pyridines are attached simultaneously to indigo carmine (IC), a dianion with two sulfonated groups (Figure 6a). The dianion enables a direct comparison of relative binding strengths of the pyridine receptors. The heterodimeric complex is massselected and subsequently fragmented. The first pyridine to leave the complex is the one which has the weaker affinity.

Figure 6 shows exemplarily two experiments with the pairs D2/D4 and D4/DC4. At low collision voltages ( $5 \mathrm{~V})$, the indigo carmine complex with D2 and D4 barely dissociates (Figure 6b), top). With increasing collision voltages, two main fragments evolve, which correspond to the doubly charged indigo carmine $(\mathrm{m} / \mathrm{z} 210)$ and the doubly charged complex of D2 with indigo carmine $(m / z 367)$. As the D4 indigo carmine complex is not detected $(\mathrm{m} / \mathrm{z}$ 403), this implies that D4 dissociates first and thus is clearly the weaker binding pyridine. A slightly different case is the D4/DC4 pair (Figure 6c): Already at low collision voltages, fragments form with high intensity. In addition to the doubly charged bare indigo carmine ion $(\mathrm{m} / z 210)$, significant signals for the D4 indigo complex $(\mathrm{m} / \mathrm{z} 403)$ and the DC4 indigo carmine complex $(\mathrm{m} / \mathrm{z} 430)$ are detected. DC4 binds slightly stronger than D4 indicated by the somewhat higher intensity of the DC4/IC intermediate. This indicates that the more rigid receptor DC4 has a higher binding affinity to indigo carmine than the flexible D4. Performing this experiment with several pairs of divalent pyridines (Figure S3, Table S3), the following ranking evolves:

$$
\text { D2 } \geq \text { DC2 > DC4 > D4 > D5 }
$$


a)<smiles></smiles>

Method C

b) $\mathrm{CID}$ of $[\mathrm{D} 2 \cdot \mathrm{D} 4 \cdot \mathrm{IC}]^{2-}$

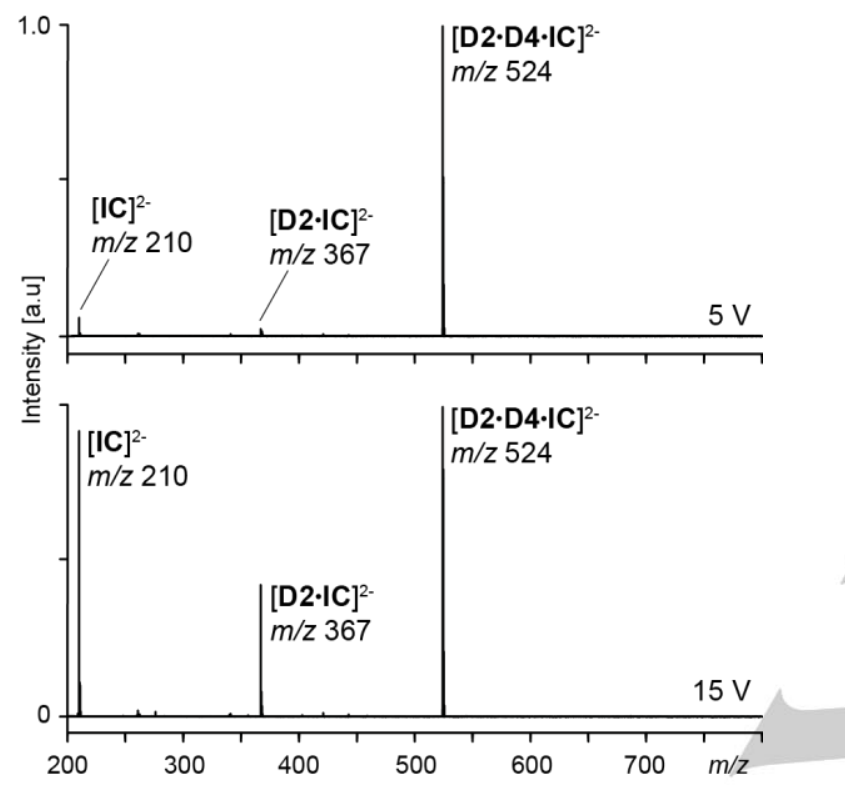

c) CID of $[\mathrm{D} 4 \cdot \mathrm{DC} 4 \cdot \mathrm{IC}]^{2-}$

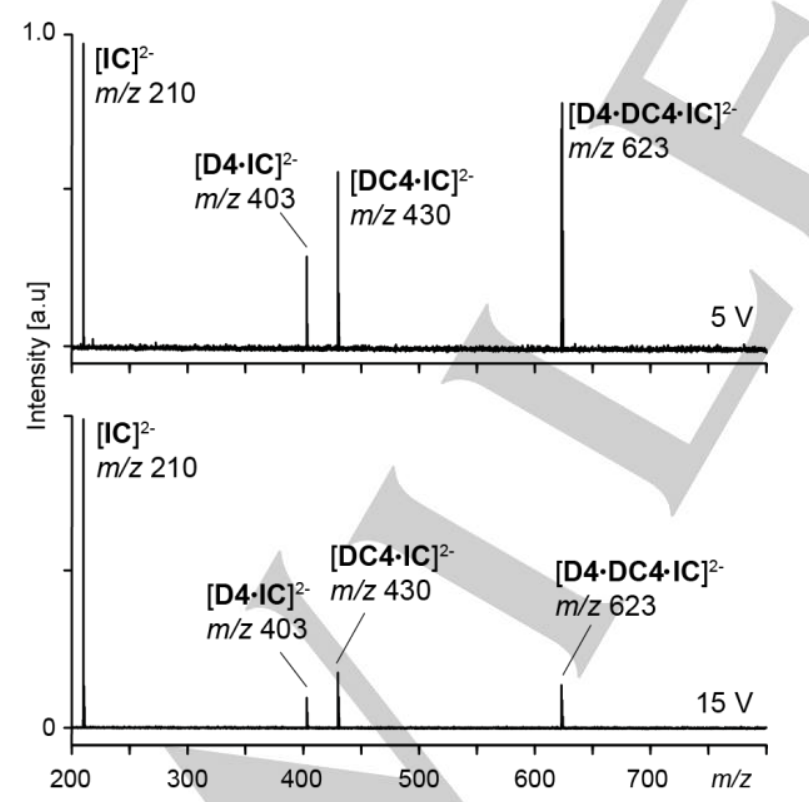

Figure 6. Method C. a) Direct comparison of the relative binding strengths with indigo carmine (IC). b) The heterodimeric complex [D2.D4.IC] $]^{2-}$ was subjected to a CID experiment. The exclusive formation of [D2.IC] ${ }^{2-}$ as primary fragment clearly shows D2 to bind stronger than D4. c) The preferential formation of $[\mathbf{D C 4} \cdot \mathbf{I C}]^{2-}$ over [D4.IC] $]^{2-}$ from mass-selected [D4.DC4.IC] $]^{2-}$ indicates a slightly higher affinity of the more rigid receptor DC4.
This experiment was not possible with all of the pyridines. For instance, DC3 does not bind to the dianion and the pairs D3/DC5 and D3/D5 form only complexes where indigo carmine is bound to two receptors of the same type (homodimers). The pair D5/DC5 forms a heterodimer, however, the interaction is too weak so that does not survive mass-selection in the quadrupole (Table S3). For the complexes, which could be ranked, the sequence is the same as those obtained with methods $A$ and $B$ - with one notable exception: D2 exhibits a similar binding strength as DC2, although its chloride complexes are weaker than those of DC2. We attribute this to the fact that indigocarmine differs in structure significantly from the small, spherical chloride anion.

Density functional calculations of anion binding with monovalent pyridines. Quantum chemical calculations were carried out to provide insight into the binding energies and binding modes of the pyridine-anion complexes. Therefore, chloride complexes with the monovalent 4-aminopyridine derivatives M1-M8 (Figure 1) were investigated at the TPSSD3(BJ)/def2-TZVP level to establish the theoretical methods with a series of model compounds. Two starting points were selected, where chloride is coordinated either in close proximity to the hydrogen atoms of the $\mathrm{N}$-methyl groups (Figure $7 \mathrm{a}$ ), or above the aromatic ring as required for an anion- $\pi$ interaction (Figure $7 b)$. The calculations reveal that an anion- $\pi$ interaction does not yield a stable minimum structure, whereas the favored binding site is in every case the coordination through $\mathrm{C}-\mathrm{H}$-..anion hydrogen bonds as depicted in Figure 7a. The distances between the chloride anion and the hydrogen atoms of the $\mathrm{N}$ methyl groups are in the range of $2.36-2.41 \AA$, which is smaller than the sum of the two van der Waals radii of hydrogen $(1.1 \AA)$ and chloride $(1.74 \AA) .{ }^{[20]}$ a)

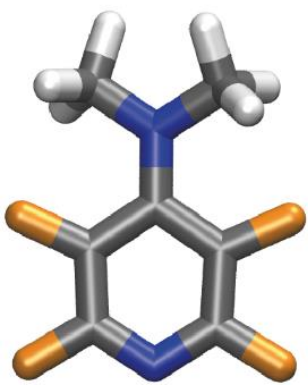

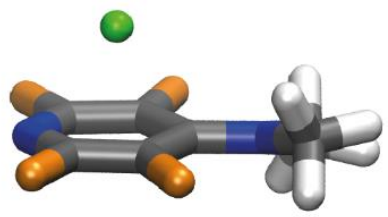

Figure 7. Starting geometries of the monovalent 4-aminopyridine $\mathbf{M} 8$ with a chloride anion attached a) through $\mathrm{C}-\mathrm{H}$...anion hydrogen bonds at the $\mathrm{N}$ methyl groups and b) through anion-m-interaction. The color code is as follows: carbon, grey; hydrogen, white; nitrogen, blue; fluorine, orange; chlorine, green.

The resulting free association enthalpies $\left(\Delta G_{a}\right)$ are summarized in Table 3. Comparing the values of the complexes of M4 with M5 (- 53.4 vs. $-70.1 \mathrm{~kJ} / \mathrm{mol}$ ) and other isomer pairs, 
which differ only in the fluorination pattern, it becomes apparent that fluorine substituents in position 2 and 6 of the pyridine ring lead to stronger binding, whereas they weaken the interaction when located in positions 3 and 5 . This can be explained by taking a closer look at the electron densities and partial charges of the aminopyridines: 2,6-fluorine substituents lead to more polarized $\mathrm{C}-\mathrm{H}$ bonds of the two coordinating $\mathrm{N}$-methyl groups and to a lower electron density at the corresponding hydrogen atoms, which strengthens the hydrogen-chloride interaction. In contrast, fluorine atoms in 3,5-position weaken the interaction due to an unfavorable $+\mathrm{M}$ effect and an electrostatic repulsion of the anion, which in total overcompensate the -1 effect of the fluorine atoms. The mono-fluorinated pyridine derivatives have similar partial charges, with only slightly deviating association enthalpies $(\sim 5 \mathrm{~kJ} / \mathrm{mol})$. Comparing the values of the nonfluorinated pyridine derivative $\mathbf{M 1}(-56.1 \mathrm{~kJ} / \mathrm{mol})$ with the perfluorinated $\mathbf{M 8}(-67.2 \mathrm{~kJ} / \mathrm{mol})$, M8 leads to more positively polarized hydrogen atoms and therefore to a stronger interaction with chloride.

Table 3. Free association enthalpies $\left(\Delta G_{a}\right)$ of the chloride complexes with monovalent and divalent fluorinated 4-aminopyridine derivatives computed at the TPSS-D3(BF)/def2-TZVP level at $T=298.15 \mathrm{~K}$

\begin{tabular}{ll|lcc}
\hline & $\Delta G_{a}[\mathrm{~kJ} / \mathrm{mol}]$ & & $\Delta G_{a}\left[\mathbf{k J} / \mathrm{mol}^{[\mathrm{a}]}\right.$ & $\Delta G_{a}\left[\mathrm{~kJ} / \mathrm{mol}^{[\mathrm{b}]}\right.$ \\
\hline M1 & -56.1 & D1 & -81.5 & - \\
M2 & -58.5 & D2 & $-118.2^{[\mathrm{c}]}$ & - \\
M3 & -63.3 & D3 & -94.0 & -68.1 \\
M4 & -53.4 & D4 & -107.9 & -80.5 \\
M5 & -70.1 & D5 & $-96.2^{[\mathrm{c}]}$ & -86.0 \\
M6 & -60.5 & DC1 & -90.8 & - \\
M7 & -72.3 & DC2 & -132.6 & - \\
M8 & -67.2 & DC3 & $-108.0^{[\mathrm{cc}]}$ & - \\
& & DC4 & -112.7 & -67.7 \\
\hline
\end{tabular}

[a] Chloride located on top of the spacer. [b] Chloride located between pyridines in close proximity to the spacer. ${ }^{[c]}$ The receptor structure in the complex closely resembles the most stable structure of the free divalent pyridine.

Density functional calculations of anion binding with divalent pyridines. TPSS-D3(BJ)/def2-TZVP density functional calculations were then performed for chloride complexes with divalent pyridine derivatives. For these receptors, several binding sites are possible and therefore different starting structures were selected. This is exemplarily shown in Figure 8 for compound DC2, in which the two pyridine units are connected by a rigid cyclohexane spacer. The chloride anion can interact with the spacer either through the hydrogen atoms of the $\mathrm{N}$-methyl groups (Figure 8a) and/or through those of the cyclohexane moiety (Figure $8 \mathrm{~b}$ ). As in the monovalent cases, structure optimizations show that chloride is always located in close proximity to hydrogen atoms and a stable minimum for a pure anion- $\pi$ interaction has never been obtained.

Table 3 lists the resulting free association enthalpies $\left(\Delta G_{a}\right)$ of chloride complexes with the divalent pyridine derivatives. Stable minima were obtained either when chloride is located on top of the spacer (a) or between the pyridine rings in close proximity to the spacer (b). $\Delta G_{a}$ values range from -68.1 to $-132.6 \mathrm{~kJ} / \mathrm{mol}$, depending on a variety of parameters that will be examined in detail below. The corrected free enthalpy contribution in the form of $\Delta G_{R R H O}$ is nearly the same for all complexes (ranging from ca. 30 to $40 \mathrm{~kJ} / \mathrm{mol}$ ). Therefore, it does not matter, whether the electronic energy or $\Delta G_{a}$ is used for discussion. No minima were obtained, where chloride was exclusively in proximity to one or two pyridine rings. In all cases, at least one $\mathrm{C}-\mathrm{H}$ bond was nearby. Divalent complexes with chloride being on top of the linker always yielded stronger associations than their counterparts, where the anion is initially placed between the pyridine rings. The energetic differences between these two binding motifs range vastly from 10 to $30 \mathrm{~kJ} / \mathrm{mol}$ and may be attributed to the lower number of possible hydrogen bonds between the rings. Generally speaking, numerous and strong $\mathrm{C}-\mathrm{H} \cdots$ anion hydrogen bonds rather than anion- $\pi$ interactions are responsible for the binding of anions to divalent pyridines. From Table 3, the following ranking evolves, with strongest to weakest association from left to right:

DC2 > D2 > DC4 > DC3 D4 > D5 DC5 D3 > DC1 > D1

Similar arguments as for the monovalent pyridines apply for the divalent receptors. A comparison of D1 vs D2, or DC1 vs DC2, further underlines the assumption that 2,6-fluorine substitution increases binding energies to chloride, whereas fluorine atoms in 3,5-position weaken these non-covalent interactions. Moreover, perfluoro-substituted compounds do not show the highest binding energies, which fully supports our experimental data. When taking a closer look at the overall trend within the row D1 to D4, electrostatic repulsion and $+\mathrm{M}$ effect of the fluorine atoms are in competition with their $-\mathrm{I}$ effect. Thus, it can be concluded that the fluorination pattern is a more important factor than the degree of fluorine substitution, as was already the case for the monovalent complexes.

The calculations also offer an explanation, why DC2 and D2 bind chloride particularly strong - as observed in the experiments as well. As the 3- and 5-positions of the pyridine are not fluorinated, the $\mathrm{C}-\mathrm{H}$ bonds at these positions participate in chloride binding with an additional $\mathrm{C}-\mathrm{H} \cdots \mathrm{Cl}$ - interaction, which cannot occur, when these positions are fluorinated. This C$\mathrm{H} \cdots$ chloride interaction exhibits a $\mathrm{H} \cdots \mathrm{Cl}$ - distance that is somewhat longer than the $\mathrm{C}-\mathrm{H} \cdots \mathrm{Cl}$ - contacts to aliphatic moieties (2.7 ̊̊ vs. $2.5 \AA$ ). Nevertheless, this additional contact contributes an additional attractive force to the anion. As these theoretical findings are in excellent agreement with the experimental trends, we conclude that indeed the $\mathrm{C}-\mathrm{H} \cdots$ anion contacts rather than anion- $\pi$ interactions are the pivotal noncovalent forces that mediate anion binding to the divalent pyridines. 
a)

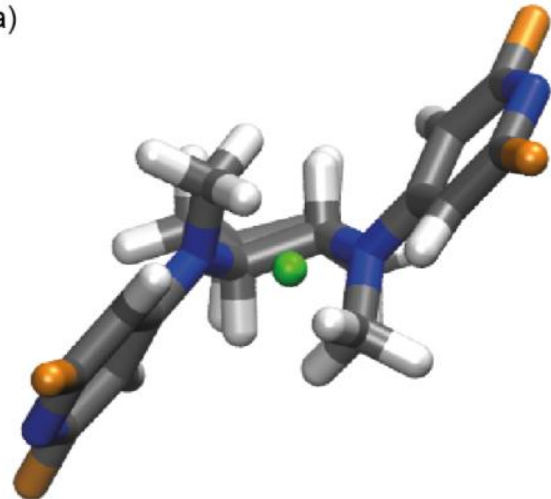

b)

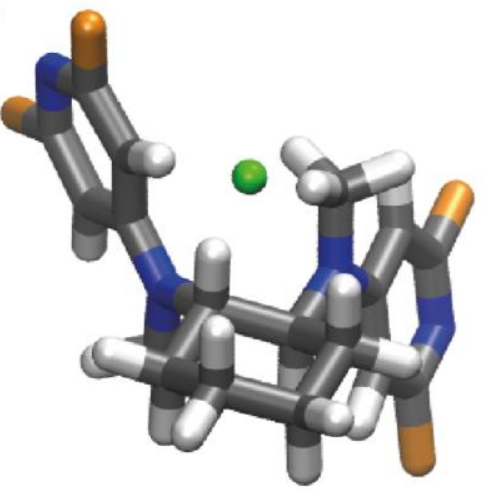

c)

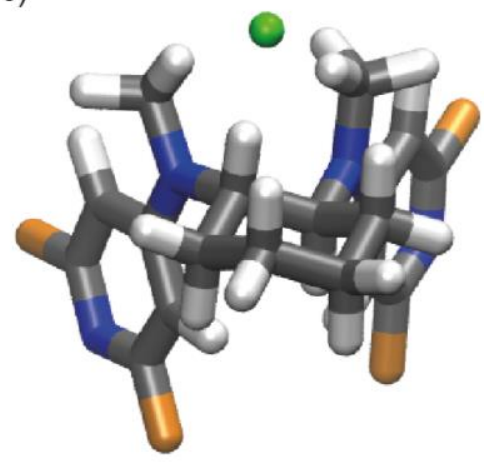

Figure 8. Optimized geometries of divalent aminopyridine derivative DC2 with a chloride anion attached. Three binding sites could be identified: a) Chloride located between the $N$-methyl groups, b) chloride located between the two pyridine rings, and c) chloride located above the cyclohexyl spacer

Comparing D1 vs. DC1, or D2 vs. DC2, indicates that a flexible spacer between the two pyridine rings leads to weaker interactions than a rigid spacer. This again strongly supports the results from mass spectrometry. However, the hydrogen bonding patterns with flexible or rigid spacer do not significantly differ from one another. In both cases, there are the same amount of linear and bent hydrogen bridges. Moreover, the $\mathrm{N}$ methyl groups in the rigid spacer case are slightly more polarized due to the higher charge stabilizing effect of the longer alkyl chain. This can be deduced from the respective atomic populations (see supporting information). It could be argued that the loss of binding energy for DC3 compared to DC2 $(\sim 25 \mathrm{~kJ} / \mathrm{mol})$ originates from its gain in rigidity. However, simultaneously we see that DC3 provides one less hydrogen bonding site than DC2, which is probably the stronger argument and better in line with the other results. The molecular structure of DC5 makes it geometrically impossible to display the same amount of $\mathrm{C}-\mathrm{H} \cdots \mathrm{Cl}^{-}$interactions as DC4. Hence, we see a major difference in binding energy $(\sim 17 \mathrm{~kJ} / \mathrm{mol})$ between the two, even though they are just stereoisomers.

The most stable structures of free divalent pyridines usually do not represent the conformations that show the strongest associations to chloride (Figure 8c). This has a crucial effect on the ranking, especially in the case of DC4. Arranging the molecule in such a way that the two $\mathrm{N}$-methyl groups point into the same direction causes the binding energy to gain around $15 \mathrm{~kJ} / \mathrm{mol}$ as compared to the assumed most stable conformation shown by the crystal structure of the free molecule (Figure 3 and supporting information). For DC1 and DC2, this also has an effect of around $9 \mathrm{~kJ} / \mathrm{mol}$, but does not change their position in the ranking. For DC5, rearranging the $\mathrm{N}$-methyl groups does not lead to a stronger binding as it does not significantly change the nature nor the number of hydrogen bonds and gives rise to an unfavorable interaction of the cyclohexane ring with the perfluorinated pyridine moiety.

Comparing these observations to the ranking of the mass spectrometric results, we see an overall good agreement of theory and experiment. There are no major differences, but only small deviations. One such deviation lies in the comparison of D2 and DC4. However, their calculated difference of association enthalpies is below $6 \mathrm{~kJ} / \mathrm{mol}$, which is not significant. DC2 is unambiguously identified as the best binding 4-aminopyridine derivative and the compounds, for that no binding could not be detected in the experiment, i.e. DC1 and D1, are the same that occur at the end of the experimental ranking with binding energies only slightly higher than those of the monovalent compounds. The preferred coordination site of the chloride anion is never directly above the pyridine ring, but always near to the $\mathrm{N}$-methyl groups. In D5 - a compound without $\mathrm{N}$-methyl groups - the chloride anion only binds in the vicinity of the ethylene spacer. Furthermore, electrostatic potential surfaces (see supporting information) indicate that despite being highly fluorinated there is still a significant amount of electron density in the area of the pyridine moieties that is very likely due to the strong electron-donating effect of the 4-amino substituents. All of these results exclude anion- $\pi$ interactions and strongly imply $\mathrm{C}-\mathrm{H} \cdots$ anion hydrogen bonding as the main binding motif.

lodide complexes with receptors D3 and DC5 could not be detected in the mass spectrometric experiments. With D5 a complex could be detected, but it was identified as one of the weakest binders. It was therefore worthwhile to compute these structures as well. A comparison of the resulting $\Delta G_{a}$ values of D3 $(-66.5 \mathrm{~kJ} / \mathrm{mol})$, DC5 $(-70.0 \mathrm{~kJ} / \mathrm{mol})$, and D5 $(-71 \mathrm{~kJ} / \mathrm{mol})$ shows a considerable weakening of association by more than $25 \mathrm{~kJ} / \mathrm{mol}$ compared to the corresponding chloride complexes. The iodide complex with receptor D5 could be detected in the experiment, but was identified as one of the weakest binders. Interestingly, the enthalpies of chloride complexes with the monovalent receptors are also around $-70 \mathrm{~kJ} / \mathrm{mol}$.

\section{Conclusions}

In this study, a series of fluoro-substituted mono- and divalent 4-aminopyridines and one divalent 4-alkoxypyridine were investigated with respect to their capability to bind anions using tandem mass spectrometry and density functional theory at the TPSS-D3(BJ)/def2-TZVP level. As the aromatic systems of these receptors are highly electron deficient, the main question was whether they interact through anion- $\pi$-interactions ( $\pi$-hole interactions) or through an alternative binding mode. The 
4-aminopyridines differ in degree and pattern of fluorine substitution, configuration, and nature of the spacer, which connects the two pyridine substituents in the divalent compounds. The experiments show that monovalent pyridines do not form detectable complexes with anions, whereas most of the divalent derivatives interact even with weakly coordinating anions. The ranking of the qualitative binding affinity from experimental data agrees nicely with the trends found in density functional calculations. The molecules with rigid spacers showed a higher or at least equal affinity to chloride than their flexible analogues. The optimized structures of the monovalent and divalent chloride complexes clearly show that the anion binds to several $\mathrm{C}-\mathrm{H}$ moieties on the spacers in the most stable structures, while anion- $\pi$ interactions do not play a substantial role. Surprisingly, the best binding receptors are not the perfluoro-substituted aminopyridines, but the 2,6-fluorinated derivatives. This is easily explained by an additional $\mathrm{C}-\mathrm{H} \cdots$ anion contact to one of the pyridine $\mathrm{C}-\mathrm{H}$ bonds. In conclusion, our results strongly indicate that the investigated fluoro-substituted 4-aminopyridine derivatives do not exhibit significant anion- $\pi$ interactions with chloride, but rather form strong hydrogen bonds with polarized $\mathrm{C}-\mathrm{H}$-bonds.

\section{Experimental Section}

For general information see Supporting Information.

The syntheses of compounds $\mathbf{M} 5^{[21]}$ and $\mathbf{M} \mathbf{8}^{[22]}$ was reported in the literature. The preparation of D1, D2, D3, D4, DC1, DC2, DC3, DC4 and DC5 has previously been reported by our group. ${ }^{[18]}$

3,5-Difluoro-(N,N-dimethylamino)pyridine (M4): 2,3,5,6-Tetrafluoro$(\mathrm{N}, \mathrm{N}$-dimethylamino)pyridine $\mathbf{M 8}(0.300 \mathrm{~g}, 1.55 \mathrm{mmol})$, titanocene difluoride $(0.050 \mathrm{~g}, 0.23 \mathrm{mmol}, 0.15$ equiv.), diphenylsilane $(1.71 \mathrm{~mL}$, $9.27 \mathrm{mmol}, 6$ equiv.) and dry 1,4-dioxane $(4 \mathrm{~mL})$ were placed into a Schlenk flask and the resulting mixture was subsequently degassed by several freeze-pump-thaw cycles. Subsequently, the mixture was heated for a few seconds with a heat gun until the yellow color changed into dark-brown and the solution was then stirred at $110^{\circ} \mathrm{C}$ for $16 \mathrm{~h}$. The reaction was quenched with methanol and water was added. Extraction with $\mathrm{Et}_{2} \mathrm{O}$, drying with $\mathrm{Na}_{2} \mathrm{SO}_{4}$, concentration and purification by FLC (hexanes/EtOAc 5:1) furnished the desired product M4 in $71 \%$ yield $(0.176 \mathrm{~g})$ as a slightly yellow oil which solidified in the fridge. ${ }^{1} \mathrm{H}$ NMR $\left(\mathrm{CDCl}_{3}, 500 \mathrm{MHz}\right): \delta=3.01\left(\mathrm{~m}_{\mathrm{c}}, 6 \mathrm{H}, \mathrm{CH}_{3}\right), 8.02\left(\mathrm{~m}_{\mathrm{c}}, 2 \mathrm{H}, \mathrm{Py}\right) \mathrm{ppm} .{ }^{13} \mathrm{C}$ $\operatorname{NMR}\left(\mathrm{CDCl}_{3}, 125 \mathrm{MHz}\right): \delta=42.7$ (q, $\left.\mathrm{CH}_{3}\right), 134.8-135.0$ (m, C-2, C-4, C6), 152.0 (dd, $\left.J_{C F}=253.9,4.4 \mathrm{~Hz}, \mathrm{C}-3, \mathrm{C}-5\right) \mathrm{ppm} .{ }^{19} \mathrm{~F} \mathrm{NMR}\left(\mathrm{CDCl}_{3}, 471\right.$ $\mathrm{MHz}$ ): $\delta=-136.9$ (s, $2 \mathrm{~F}, 3-\mathrm{F}, 5-\mathrm{F})$ ppm. HRMS (ESI-TOF): calcd. for $\mathrm{C}_{7} \mathrm{H}_{8} \mathrm{~F}_{2} \mathrm{~N}_{2}: 159.0734[\mathrm{M}+\mathrm{H}]^{+}$; found: 159.0731 .

1,2-Bis[(2,3,5,6-tetrafluoropyridine-4-yl)oxy]ethane (D5): Ethylene glycol $(0.148 \mathrm{~g}, 2.38 \mathrm{mmol})$, pentafluoropyridine $(0.81 \mathrm{~g}, 4.79 \mathrm{mmol}, 2$ equiv.) and $\mathrm{K}_{2} \mathrm{CO}_{3}(0.794 \mathrm{~g}, 5.75 \mathrm{mmol}$ ) were dissolved in DMSO $(5 \mathrm{~mL})$ and stirred for $16 \mathrm{~h}$ at $\mathrm{rt}$. After addition of water extraction with $\mathrm{Et}_{2} \mathrm{O}$ and purification by FLC (hexanes/EtOAc 6:1) furnished product D5 in $49 \%$ yield $(0.425 \mathrm{~g})$ as a colorless oil, which solidified in the fridge. ${ }^{1} \mathrm{H}$ NMR $\left(\mathrm{CDCl}_{3}, 500 \mathrm{MHz}\right): \delta=4.87\left(\mathrm{~m}_{\mathrm{c}}, 4 \mathrm{H}, \mathrm{CH}_{2}\right) \mathrm{ppm} .{ }^{13} \mathrm{C} \mathrm{NMR}\left(\mathrm{CDCl}_{3}, 125\right.$ $\mathrm{MHz}): \delta=72.7\left(\mathrm{t}, \mathrm{CH}_{2}\right), 135.1,144.4,146.8(3 \mathrm{mc}, \mathrm{C}-2, \mathrm{C}-3, \mathrm{C}-4, \mathrm{C}-5, \mathrm{C}-$ 6) $\mathrm{ppm} .{ }^{19} \mathrm{~F} \mathrm{NMR}\left(\mathrm{CDCl}_{3}, 471 \mathrm{MHz}\right): \delta=-158.6\left(\mathrm{~m}_{\mathrm{c}}, 4 \mathrm{~F}, 3-\mathrm{F}, 5-\mathrm{F}\right),-89.9$ $\left(\mathrm{m}_{\mathrm{c}}, 4 \mathrm{~F}, 2-\mathrm{F}, 6-\mathrm{F}\right)$ ppm. HRMS (ESI-TOF): calcd. for $\mathrm{C}_{12} \mathrm{H}_{4} \mathrm{~F}_{8} \mathrm{~N}_{2} \mathrm{O}_{2}$ : $361.0223[\mathrm{M}+\mathrm{H}]^{+}$; found: 361.0228 .

Mass spectrometric experiments. Tetra- $n$-butylammonium salts were purchased from Sigma Aldrich (Taufkirchen, Germany). Samples for electrospray-ionization mass spectrometric experiments were prepared by adding the corresponding pyridine and the corresponding tetra- $n$ butylammonium salt in equimolar amounts. Therefore, a $0.5 \mathrm{mM}$ stock solution of the pyridines in dichloromethane was mixed with a $2 \mathrm{mM}$ tetra- $n$-butylammonium anion salt acetonitrile solution in a 4 to 1 ratio to obtain a concentration of $400 \mu \mathrm{M}$ each (method B). For experiments following method $\mathrm{A}$ equimolar amounts of two pyridines were mixed analogous with the corresponding anion solution. Mesylate complexes did not form at a 1:1 pyridine:anion ratio, so they were mixed in a 1:5 pyridine:anion excess. For experiments of method $\mathrm{C}$ a $1 \mathrm{mM}$ indigocarmine solution $\left(\mathrm{H}_{2} \mathrm{O}: \mathrm{MeOH} 1: 1\right)$ was mixed with the two desired pyridines and diluted to a final concentration of $50 \mu \mathrm{M}$ pyridine and 25 $\mu \mathrm{M}$ indigocarmine.

Method A and C: Electrospray-ionization (ESI) mass spectra of anion/pyridine complexes were recorded in negative ion mode on an Ionspec QFT-7 FT-ICR mass spectrometer (Agilent/lonspec, Lake Forest, $\mathrm{CA}$, USA), equipped with a $7 \mathrm{~T}$ superconducting magnet and a Micromass Z-spray electrospray ionization source (Waters Co., SaintQuentin, France). The sample solutions were introduced into the ion source at flow rates of $4 \mu \mathrm{L} / \mathrm{min}$. A constant spray and highest intensities were achieved with a capillary voltage of $3.8-4.2 \mathrm{~V}$ and a source temperature of $40^{\circ} \mathrm{C}$. The parameters for sample cone and extractor cone voltages as well as the ion optics were optimized for maximum abundances of the desired complex ions. Multiple scans (up to 50) were averaged for each spectrum in order to improve the signal-to-noise ratio. Collision-induced dissociation (CID) was achieved by employing an isolation function for the cyclotron frequencies of the two corresponding pyridine anion complexes and integrating a $5 \mathrm{~ms}$ gas pulse in the setup.

Method B: Electrospray ionization quadrupole-time-of-flight highresolution mass spectrometric (ESI-Q-TOF-HRMS) experiments were performed with a Synapt G2-S HDMS (Waters Co., Milford, MA, USA) in negative ion mode. Typical instrument parameters were as follows: flow rate: $20 \mu \mathrm{L} \mathrm{min}{ }^{-1}$; capillary voltage: $1.6 \mathrm{kV}$; sample cone voltage: $10 \mathrm{~V}$; source offset: $80 \mathrm{~V}$; nebulizer gas: 6 bar; desolvation gas flow: $500 \mathrm{~L} / \mathrm{h}$. Near these settings, these parameters were optimized for maximum abundance of the desired intact [M-anion] complex and minimum abundance of the corresponding gas-phase fragmentation products. CID experiments were employed for MS/MS experiments with $\mathrm{Ar}$ as the fragmentation gas. Complex ions of interest were $\mathrm{m} / \mathrm{z}$-selected in the quadrupole region and fragmented in the transfer cell with increasing collision energies from 0 to $12 \mathrm{~V}$.

Quantum chemical calculations. The fluorinated aminopyridine derivatives and their anion complexes were investigated by density functional theory (DFT) at the TPSS-D3(BJ)/def2-TZVPP ${ }^{[23]}$ level. D3(BJ) refers to Grimme's D3 dispersion correction ${ }^{24]}$ with Becke-Johnson damping. ${ }^{[25]}$ We opted for this meta-GGA functional due to its outstanding performance in terms of computational efficiency, especially in combination with the RI-DFT ${ }^{[26]}$ method. Preliminary work showed that this level of theory competes well with wavefunction-based MP2/ccpVTZ ${ }^{[27]}$ calculations (see supporting information). All structures were fully optimized, whereby local minima were verified via normal mode analyses showing no imaginary frequencies. With these optimized structures, free enthalpies of association $\left(\Delta G_{a}\right)$ were computed by a method proposed by Grimme ${ }^{[28]}$ that incorporates a so-called rigid-rotor harmonic-oscillator approximation (RRHO) as a correction to low-lying frequencies, which often show anharmonicites: ${ }^{[29]} \Delta \mathrm{G}_{\mathrm{a}}=\Delta \mathrm{E}^{\mathrm{CP}}+\Delta \mathrm{G}_{\mathrm{RRHO}}$. 
$\triangle \mathrm{E}^{\mathrm{CP}}$ is the counterpoise-corrected (CP) binding energy as described by Boys and Bernardi[30] to account for basis set superposition error (BSSE) and $\Delta G_{R R H O}$ is the corrected free enthalpic contribution. Further explanations can be found in the designated literature. All calculations were performed with the program package TURBOMOLE ${ }^{[31]}$ (version 7.0.1). For every pyridine derivative, several binding motifs were computed, whereby always the lowest binding energies are presented.

\section{Acknowledgements}

We thank Dr. Andreas Springer for introducing M.G. to the mass spectrometers and for inspiring discussions. This work was made possible using the High-Performance Computing resources of the Zentraleinrichtung für Datenverarbeitung (ZEDAT) of Freie Universität Berlin. Funding from the Deutsche Forschungsgmeinschaft (CRC 765 and GK 1582) is gratefully acknowledged.

Keywords: fluorinated pyridines $\cdot$ anion- $\pi$ interactions $\cdot \mathrm{C}-\mathrm{H}-$ anion interactions $\bullet$ tandem mass spectrometry $\bullet$ density functional theory

\section{References}

[1] a) C. L. Perrin, J. B. Nielson, Annu. Rev. Phys. Chem. 1997, 48, 511544; b) I. Alkorta, J. Elguero, Chem. Soc. Rev. 1998, 27, 163-170.

[2] S. Grimme, Angew. Chem. Int. Ed. 2008, 47, 3430-3434.

[3] D. A. Dougherty, Science 1996, 271, 163-168.

[4] a) P. Gamez, T. J. Mooibroek, S. J. Teat, J. Reedijk, Acc. Chem. Res 2007, 40, 435-444; b) B. L. Schottel, H. T. Chifotides, K. R. Dunbar, Chem. Soc. Rev. 2008, 37, 68-83; c) T. J. Mooibroek, C. A. Black, P. Gamez, J. Reedijk, Cryst. Growth Des. 2008, 8, 1082-1093; d) O. B. Berryman, D. W. Johnson, Chem. Commun. 2009, 3143-3153; e) A. Frontera, P. Gamez, M. Mascal, T. J. Mooibroek, J. Reedijk, Angew. Chem. Int. Ed. 2011, 50, 9564-9583; f) M. Giese, M. Albrecht, K. Rissanen, Chem. Rev. 2015, 115, 8867-8895; g) M. Giese, M. Albrecht, K. Rissanen, Chem. Commun. 2016, 52, 1778-1795

[5] B. P. Hay, V. S. Bryantsev, Chem. Commun. 2008, 0, 2417-2428.

[6] I. Alkorta, I. Rozas, J. Elguero, J. Am. Chem. Soc. 2002, 124, 85938598.

[7] H. Schneider, K. M. Vogelhuber, F. Schinle, J. M. Weber, J. Am. Chem Soc. 2007, 129, 13022-13026.

[8] a) K. Hiraoka, S. Mizuse, S. Yamabe, The Journal of Physical Chemistry 1987, 91, 5294-5297; b) H.-J. Schneider, F. Werner, T. Blatter, J. Phys. Org. Chem. 1993, 6, 590-594; c) H.-J. Schneider, Angew. Chem. Int. Ed. 2009, 48, 3924-3977.

[9] D. Quiñonero, C. Garau, C. Rotger, A. Frontera, P. Ballester, A. Costa, P. M. Deyà, Angew. Chem. Int. Ed. 2002, 41, 3389-3392.

[10] M. Mascal, A. Armstrong, M. D. Bartberger, J. Am. Chem. Soc. 2002, $124,6274-6276$.

[11] a) M. Wenzel, J. R. Hiscock, P. A. Gale, Chem. Soc. Rev. 2012, 41, 480-520; b) S. Chakravarty, Z.-Z. Sheng, B. Iverson, B. Moore, FEBS Lett. 2012, 586, 4180-4185.

[12] a) V. Gorteau, G. Bollot, J. Mareda, A. Perez-Velasco, S. Matile, J. Am Chem. Soc. 2006, 128, 14788-14789; b) J. Mareda, S. Matile, Chem.
Eur. J. 2009, 15, 28-37; c) R. E. Dawson, A. Hennig, D. P. Weimann, D. Emery, V. Ravikumar, J. Montenegro, T. Takeuchi, S. Gabutti, M. Mayor, J. Mareda, C. A. Schalley, S. Matile, Nat. Chem. 2010, 2, 533 538; d) A. Vargas Jentzsch, D. Emery, J. Mareda, P. Metrangolo, G. Resnati, S. Matile, Angew. Chem. Int. Ed. 2011, 50, 11675-11678.

[13] a) Y. S. Rosokha, S. V. Lindeman, S. V. Rosokha, J. K. Kochi, Angew. Chem. Int. Ed. 2004, 43, 4650-4652; b) B. L. Schottel, H. T. Chifotides, M. Shatruk, A. Chouai, L. M. Pérez, J. Bacsa, K. R. Dunbar, J. Am. Chem. Soc. 2006, 128, 5895-5912; c) G. Gil-Ramírez, E. C. EscuderoAdán, J. Benet-Buchholz, P. Ballester, Angew. Chem. Int. Ed. 2008, 47 4114-4118; d) H. T. Chifotides, B. L. Schottel, K. R. Dunbar, Angew. Chem. Int. Ed. 2010, 49, 7202-7207; e) M. Giese, M. Albrecht, C. Bannwarth, G. Raabe, A. Valkonen, K. Rissanen, Chem. Commun. 2011, 47, 8542-8544; f) M. Giese, M. Albrecht, C. Plum, D. Hintzen, A. Valkonen, K. Rissanen, Supramol. Chem. 2012, 24, 755-761; g) D.-X Wang, M.-X. Wang, J. Am. Chem. Soc. 2012, 135, 892-897; h) H. T. Chifotides, K. R. Dunbar, Acc. Chem. Res. 2013, 46, 894-906; i) M. Albrecht, H. Yi, O. Köksal, G. Raabe, F. Pan, A. Valkonen, K. Rissanen, Chem. Eur. J. 2016, 22, 6956-6963; j) A. Kim, R. Ali, S. H. Park, Y.-H. Kim, J. S. Park, Chem. Commun. 2016, 52, 11139-11142; k) L. M. Eytel, A. K. Gilbert, P. Görner, L. N. Zakharov, D. W. Johnson, M. M. Haley Chem. Eur. J. 2017, 23, 4051-4054; I) Y.-Z. Liu, K. Yuan, L. Liu, Z. Yuan, Y.-C. Zhu, J. Phys. Chem. A 2017, 121, 892-900.

[14] B. P. Hay, R. Custelcean, Cryst. Growth Des. 2009, 9, 2539-2545.

[15] a) W. D. Price, P. D. Schnier, E. R. Williams, J. Phys. Chem. B 1997 101, 664-673; b) E. C. Kampen, J. S. Brodbelt, Anal. Chem. 2000, 72 5411-5416; c) P. B. Armentrout, Top. Curr. Chem. 2003, 225, 233-262.

[16] A. Memboeuf, A. Nasioudis, S. Indelicato, F. Pollreisz, A. k. Kuki, S. n. Kéki, O. F. van den Brink, K. r. Vékey, L. s. Drahos, Anal. Chem. 2010 82, 2294-2302.

[17] R. Graham Cooks, J. S. Patrick, T. Kotiaho, S. A. McLuckey, Mass Spectrom. Rev. 1994, 13, 287-339.

[18] a) G. Podolan, D. Lentz, H.-U. Reissig, Angew. Chem. Int. Ed. 2013, 52 9491-9494; b) G. Podolan, P. Jungk, D. Lentz, R. Zimmer, H.-U. Reissig, Adv. Synth. Catal. 2015, 357, 3215-3228.

[19] L. J. Farrugia, J. Appl. Crystallogr. 1997, 30, 565.

[20] A. Bondi, The Journal of Physical Chemistry 1964, 68, 441-451.

[21] M. Schlosser, C. Bobbio, T. Rausis, J. Org. Chem. 2005, 70, 24942502

[22] R. Ranjbar-Karimi, M. Mashak-Shoshtari, A. Darehkordi, Ultrason. Sonochem. 2011, 18, 258-263.

[23] a) J. Tao, J. P. Perdew, V. N. Staroverov, G. E. Scuseria, Phys. Rev. Lett. 2003, 91, 146401; b) F. Weigend, R. Ahlrichs, PCCP 2005, 7, 3297-3305.

[24] S. Grimme, J. Antony, S. Ehrlich, H. Krieg, J. Chem. Phys. 2010, 132 154104.

[25] S. Grimme, S. Ehrlich, L. Goerigk, J. Comput. Chem. 2011, 32, 14561465.

[26] M. Von Arnim, R. Ahlrichs, J. Comput. Chem. 1998, 19, 1746-1757

[27] T. H. D. Jr., J. Chem. Phys. 1989, 90, 1007-1023.

[28] S. Grimme, Chem. Eur. J. 2012, 18, 9955-9964.

[29] P. Y. Ayala, H. B. Schlegel, J. Chem. Phys. 1998, 108, 2314-2325.

[30] S. B. Boys, F. Bernardi, Mol. Phys. 1970, 19, 553-566

[31] R. Ahlrichs, M. Bär, M. Häser, H. Horn, C. Kölmel, Chem. Phys. Lett. 1989, 162, 165-169. 
Entry for the Table of Contents (Please choose one layout)

Layout 1:

\section{FULL PAPER}

Text for Table of Contents

Layout 2:

\section{FULL PAPER}

((Insert TOC Graphic here; max. width: $11.5 \mathrm{~cm}$; max. height: $2.5 \mathrm{~cm})$ )

Author(s), Corresponding Author(s)*

Page No. - Page No.

Title

((Insert TOC Graphic here: $\max$. width: $5.5 \mathrm{~cm}$; max. height: $5.0 \mathrm{~cm})$ )
Author(s), Corresponding Author(s)*

Page No. - Page No.

Title

\section{tle}

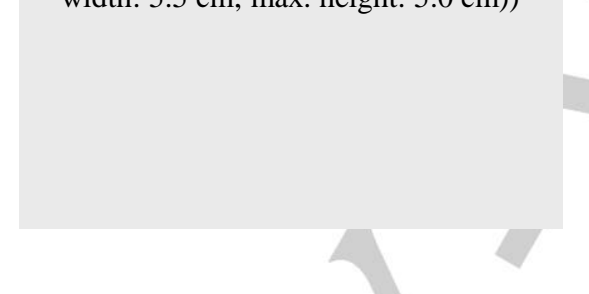

